Research Article

\title{
Simulation and Experimental Study on the Discontinuous Dynamic Impact on Unidirectional Confined Coal-Rock Damage
}

\author{
Tao Wang $\mathbb{D}^{1},{ }^{1,2}$ Hongbao Zhao $\mathbb{D}^{1,2}$ Yang Li, ${ }^{2}$ Huan Zhang $\mathbb{D}^{2},{ }^{2}$ and Nansong $\mathrm{Ju}^{2}$ \\ ${ }^{1}$ State Key Laboratory of Oil and Gas Reservoir Geology and Exploitation, Southwest Petroleum University, \\ Chengdu 610500, China \\ ${ }^{2}$ School of Energy and Mining Engineering, China University of Mining \& Technology, Beijing 100083, China
}

Correspondence should be addressed to Hongbao Zhao; hongbaozhao@126.com

Received 29 October 2018; Revised 11 January 2019; Accepted 27 March 2019; Published 2 May 2019

Academic Editor: Itzhak Green

Copyright (c) 2019 Tao Wang et al. This is an open access article distributed under the Creative Commons Attribution License, which permits unrestricted use, distribution, and reproduction in any medium, provided the original work is properly cited.

The deformation and the damage characteristics of coal and rock under different restraint static load and different impact velocity were studied with the FEM software LS-DYNA. Based on this, the influence of impact load on the damage of coal rock under onedimensional constraint condition was studied by using the self-developed constrained pendulum impact dynamic loading test device and ultrasonic testing device. The results show that the deformation of coal and rock increases with the increase of impact velocity and decreases firstly and then remains constant with the increase of constraint static load; when the constraint static load exceeds the compression strength, the displacement increases rapidly and the coal collapses at a strike; the damage quantity of coal and rock has a cumulative effect, and the damage quantity increases with the increase of impact number; when the constraint static load is identical, the increase of impulse contributes to microcrack propagation, and the damage quantity of coal and rock accelerates with the increase of single impact impulse; when the impulse is identical, the constraint static load restrains the microcrack propagation, and the damage quantity of coal and rock decelerates with the increase of constraint static load; the complete damage quantity range of coal and rock is $0.65 \sim 0.75$. In order to fully destroy the coal and rock, if the single horizontal impulse is greater, the number of shocks needed is less; if the constrained static load is greater, the more impact times are needed.

\section{Introduction}

As an important engineering material, the rock is often in a complex combined stress environment. The instability of rock materials under the action of external loads threatens the safe production of rock engineering. The pillars in mining bear the weight of overlying strata and may be subjected to blasting, mechanical, and other dynamic loads. The related engineering problems can be simplified to study the effect of dynamic impact on rock damage under unidirectional restraint. The rock is damaged by external loads, and its nature is the result of the microcrack structural evolution inside the rock. That is to say, the macrodamage of the rock caused by dynamic impact under unilateral constraints is the overall reflection of the internal microcrack structural evolution [1].
Many scholars have studied the dynamics damage of rock: Shan et al. proved the feasibility of testing the dynamic total stress-strain curve of rock using the SHPB device [2]. Weng et al. conducted one-dimensional, two-dimensional, and three-dimensional dynamic and static combined loading tests on rocks based on the modified SHPB test system and studied the rock deformation and strength characteristics, energy transmission laws and failure mode, etc. [3-6]. Fakhimi et al. used SHPB to evaluate the strength characteristics of sandstone under uniaxial compressive loading. The results suggest that rock strength increases under dynamic loading [7]; Jin et al. studied and analyzed the failure mode and mechanism as well as definition method of damage variable of sandstone under the combined action of static load and cyclic impact [8]. Zhu et al. simulated the deformation and failure process of rock under 
combined static and dynamic loading by the Rock Failure Process Analysis for Dynamics [9]; Zhao et al. conducted the drop-weight test on the briquettes and analyzed the development and evolution laws of internal microstructure and new surface cracks under the action of different impact loads [10]; Yavuz et al. found that dynamic compressive strength of rocks increases with increase in loading rate and/ or increase in rock property values except porosity [11]. Lindholm et al. and Kinoshita et al. described the dynamic mechanical behavior of rock by the over stress model $[12,13]$.

The traditional research method of rock dynamic mechanics is to apply the cyclic impact load, and to conduct the statistics of dissipative energy diffusion laws and the crack propagation of rock, for giving the dynamic mechanical properties of rock. However, the damage law of coal and rock under dynamic and static combination state is still rare. In order to fully understand the dynamic characteristics of coal and rock and to evaluate the stability of rock engineering more accurately, it is necessary to study the mechanical response of coal and rock mass under the joint action of static and dynamic loads.

In this paper, the damage model of coal and rock was established by numerical analysis software ANSYS, and the influence of impact velocity and restrained static load on the deformation of coal and rock mass was analyzed. Then, based on ultrasonic wave speed as an indicator, the evolution law of coal and rock damage under combined action of static and dynamic loads was studied from a mesoscale, and the influence of constraint static load, impact load, and impact number on the coal-rock damage was analyzed. The unilateral constraint dynamic impact model is shown in Figure 1.

It can be seen from Figure 1 that there are two kinds of unilateral constraint dynamic impact models: the static load $P_{\mathrm{s}}$ and the impact load $P_{\mathrm{d}}$ are in the same direction and the static load $P_{\mathrm{s}}$ and the impact load $P_{\mathrm{d}}$ are perpendicular to each other. In this paper, a one-way constraint dynamic impact model with static load and impact load perpendicular to each other is adopted (see Figure 1(b)).

\section{Numerical Simulation Research on Dynamic and Static Combination}

The numerical simulation research in this paper mainly considers the influence of impact velocity and constraint static load on the evolution of coal-rock damage, expects to find out the failure laws of coal and rock under the above external conditions, analyzes the influence degree of the magnitude of impact velocity and constraint static load on the damage of coal and rock, analyzes the failure mode of coal and rock from the theoretical point of view, tries to get its universal laws, and provides the theoretical guidance for efficient mining of coal and improving the impact resistance of pillars.

2.1. Modeling and Parameter Settings. In this paper, the model is classified by impulse and constrained static load. In order to study the damage evolution of impulse magnitude

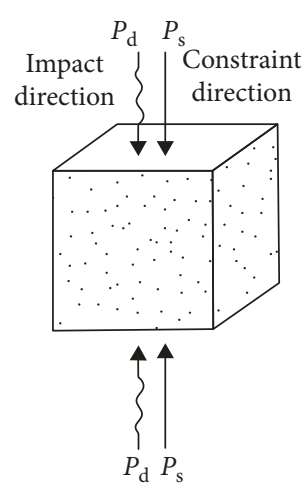

(a)

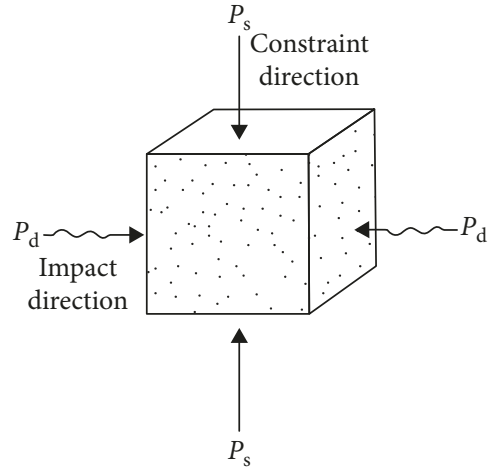

(b)
Figure 1: Unilateral constraint dynamic impact model.

on coal and rock, the simulation process applied the same constraint static load to the coal-rock model, conducted a comparative analysis by changing the impulse magnitude, applied the same-sized constraint static load $P_{\mathrm{d}}$ to the square coal-rock models (a) to (f), and gradually increased the impulses from (a) to (f). When studying the damage evolution of constraint static load on coal and rock, the simulation process applied the same impulse to the coal-rock model, conducted a comparative analysis by changing the magnitude of constraint static load, applied the same-sized impulse $P_{\mathrm{s}}$ to the square coal-rock models (a) to (f), and gradually increased the constraint static loads from (a) to (f). Considering the actual conditions of the coal-rock deposits, a steel plate was placed at the bottom of the sample. The bottom of the steel plate was fixed.

The square coal-rock model is a cube with a side length of $70 \mathrm{~mm}$. The model was divided into $35 * 35 * 35=42875$ units. This simulation test used a cylinder with a diameter of $60 \mathrm{~mm}$ and a height of $40 \mathrm{~mm}$ to perform the impact, and the impact loading model is shown in Figure 2. The loading gradient of confined static stress was $0-5 \mathrm{Mpa}$. The impulse was converted into the loading velocity of the cylinder according to the laboratory test, and its loading velocity was $2.08-5.48 \mathrm{~m} / \mathrm{s}$ respectively. A total of 12 models were simulated, and the contact time was assumed to be $0.01 \mathrm{~s}$. The loading mechanical parameters of each model are shown in Table 1. The physical and mechanical parameters used in the calculation were based on briquette coal. The mechanical parameters used in the calculation are shown in Table 2. Based on the Holmquist-Johnson-Cook constitutive model of LS-DYNA finite element analysis software, the coal-rock impact test simulation is realized $[14,15]$. The HJC constitutive model is shown in Figure 3.

2.2. Calculation Results and Analysis. In order to facilitate the description and analysis of the model results, a schematic diagram of the loading of coal-rock model was drawn, the surface where the impulse is applied is defined as the impact surface, the two side surfaces where the constraint static load is applied are the constraint static surfaces, and the surface without any load is the free surface. According to the force range of the impact surface, it can be divided into bearing 


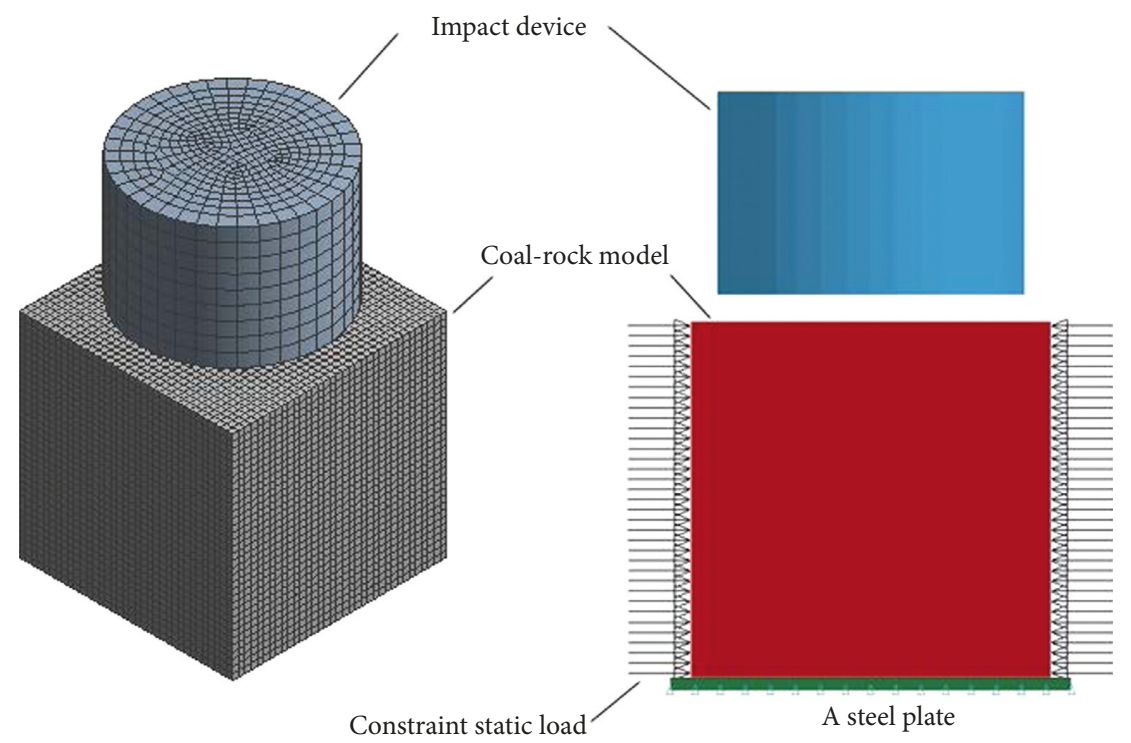

FIGURE 2: Schematic diagram of simulated impact loading.

TABle 1: Model loading mechanics parameters.

\begin{tabular}{lccc}
\hline Model & Nor & Constraint static load MPa & Impact velocity m/s \\
\hline & a & 2 & 2.08 \\
& b & 2 & 2.94 \\
Impulse model & $\mathrm{c}$ & 2 & 3.60 \\
& $\mathrm{~d}$ & 2 & 4.15 \\
& $\mathrm{e}$ & 2 & 4.64 \\
& $\mathrm{f}$ & 2 & 5.48 \\
\hline & $\mathrm{a}$ & 0 & 2.08 \\
Constraint static load model & $\mathrm{b}$ & 1 & 2.08 \\
& $\mathrm{c}$ & 2 & 2.08 \\
& $\mathrm{~d}$ & 3 & 2.08 \\
& $\mathrm{e}$ & 4 & 2.08 \\
& $\mathrm{f}$ & 5 & 2.08 \\
\hline
\end{tabular}

TABLE 2: Mechanical parameters used in the calculation.

\begin{tabular}{lccccc}
\hline Density $\mathrm{kg} / \mathrm{m}^{3}$ & Elastic modulus GPa & Compressive strength MPa & Poisson's ratio & Damage factor $D_{1}$ & Damage factor $D_{2}$ \\
\hline 1428 & 0.81 & 5.6 & 0.3 & 0.04 & 1 \\
\hline
\end{tabular}

surface area, crossed area, and nonbearing surface area, as shown in Figure 4.

According to the constraint static load and impulse loading conditions, the coal-rock model was numerically simulated to obtain the displacement of the dynamic and static combined loading model. Take the model of impact load (No. (b) as an example), as shown in Figure 5.

As can be seen from Figure 5(c), the $z$-direction displacement value of the surface of coal under impact has regional characteristics. The displacement in the bearing surface area is the largest, the crossed area is the second, and the nonbearing surface area is the smallest. The displacement direction of the bearing surface area and the crossed area is the same as the impact direction, while the displacement direction of the nonbearing surface area is opposite to the impact direction. After the impact, the rock mass in the nonimpact area will be subjected to the swelling and extrusion effect of the rock mass in the impact area, resulting in the reverse displacement of the nonimpact area. Due to the weak expansion and extrusion effect, the surface displacement of the nonimpact area is very small.

As can be seen from Figures 5(a) and 5(b), the transverse deformation of coal and rock is caused by impact. The $Y$ displacement is less than the $X$-displacement due to the constraint static load in the $y$-direction.

2.2.1. Influence of Impulse Magnitude on Damage of CoalRock Model. The simulation conditions are as follows: the constraint static load is $2 \mathrm{MPa}$ and the initial velocity given to the cylinder is $2.08 \mathrm{~m} / \mathrm{s}-5.48 \mathrm{~m} / \mathrm{s}$. The simulated results of effective strain and impact velocity of the coal-rock model are obtained by loading the coal-rock model according to the above conditions, as shown in Figure 6. With the increase of 


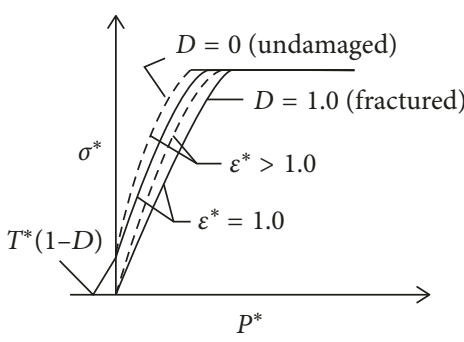

(a)

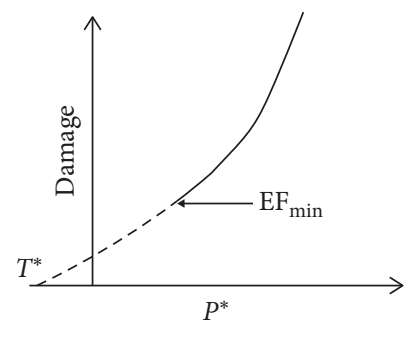

(b)

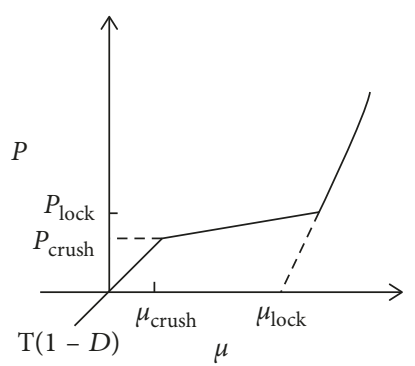

(c)

FIgURE 3: Holmquist-Johnson-Cook constitutive model.

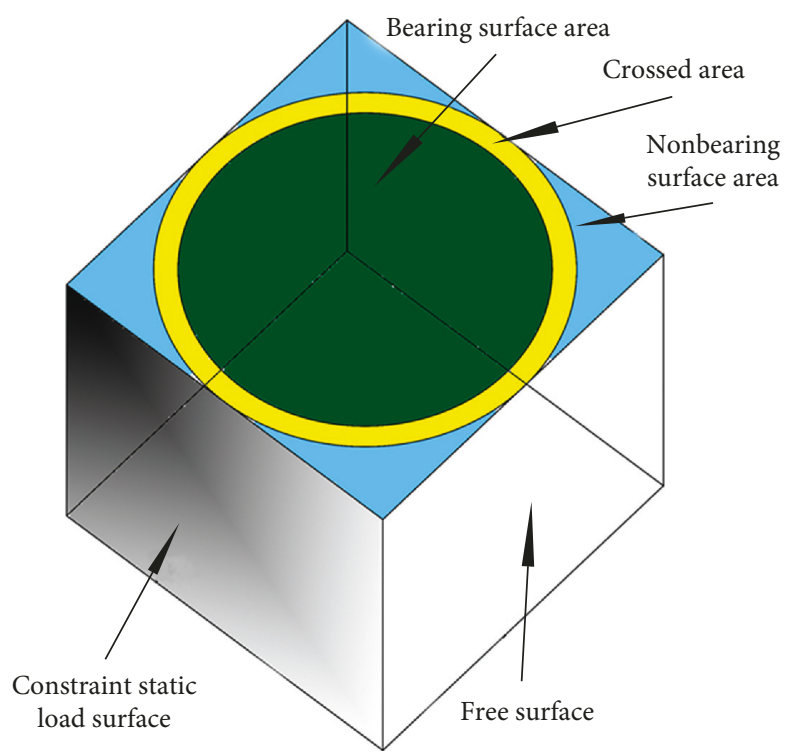

FIGURE 4: Conventions of each surface of coal-rock model.

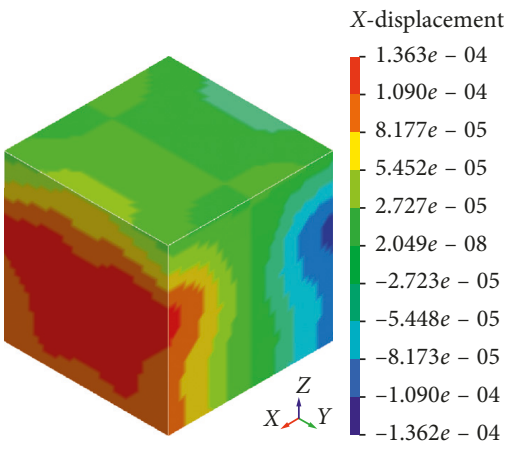

(a)

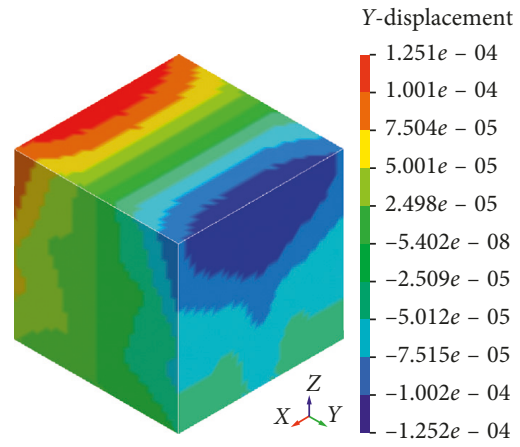

(b)

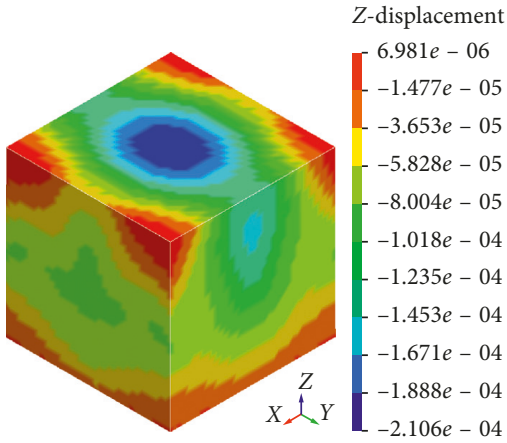

(c)

Figure 5: Displacement of dynamic and static combined loading model. (a) X-displacement. (b) Y-displacement. (c) Z-displacement.

impact velocity, the effective strain of coal after impact increases gradually and the damage degree of coal increases gradually. When the impact velocity is $2.08 \mathrm{~m} / \mathrm{s}$ or $2.94 \mathrm{~m} / \mathrm{s}$, there is no obvious damage on the surface of the coal sample. When the impact velocity is $3.60 \mathrm{~m} / \mathrm{s}$ or $4.15 \mathrm{~m} / \mathrm{s}$, the phenomenon of slag failure occurs around the coal sample. When the impact velocity is $4.64 \mathrm{~m} / \mathrm{s}$, obvious damage occurs in the impact crossed area, and partial damage occurs in the nonbearing surface area. When the impact velocity is $5.48 \mathrm{~m} / \mathrm{s}$, obvious damage occurs in the crossed area and around the sample surfaces, and the sample loses the ability to resist the impact.

The resultant displacements of the bearing surface area and the crossed area are extracted to obtain the displacement 


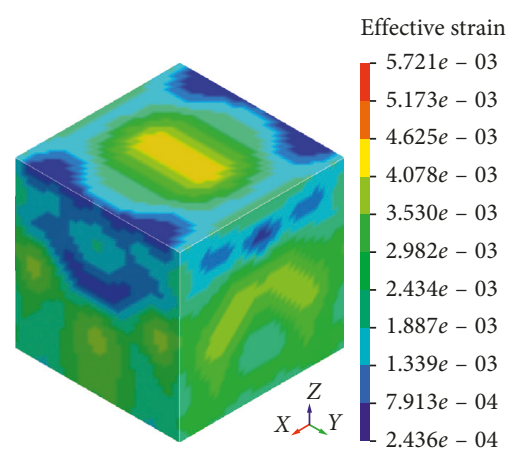

(a)

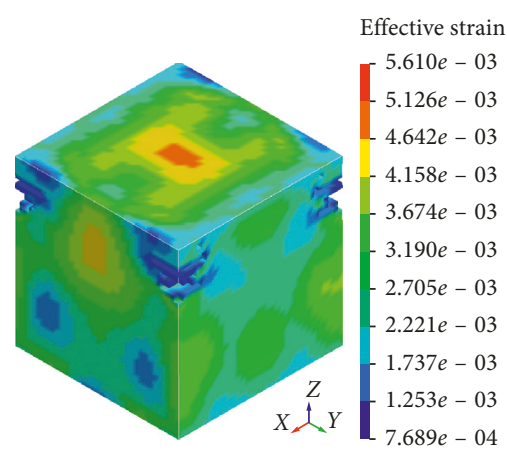

(d)

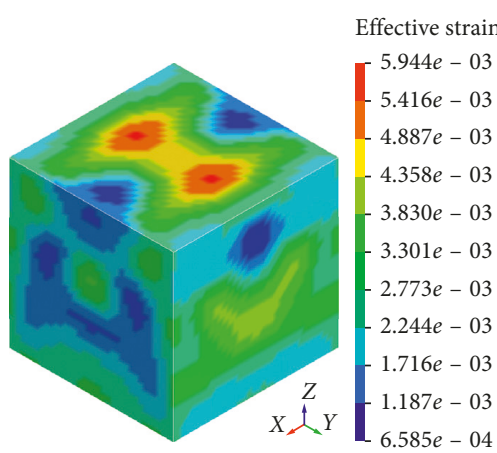

(b)

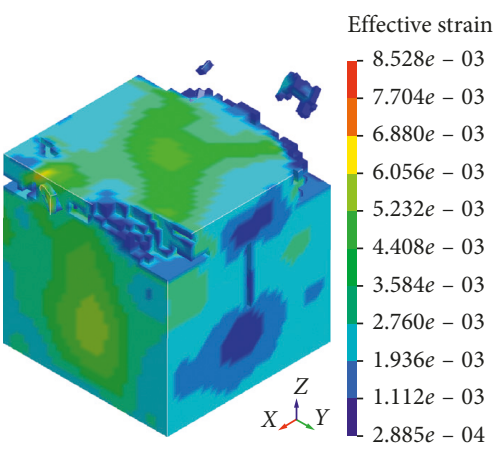

(e)

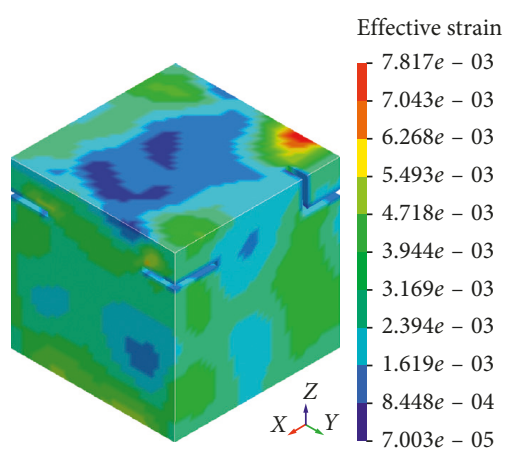

(c)

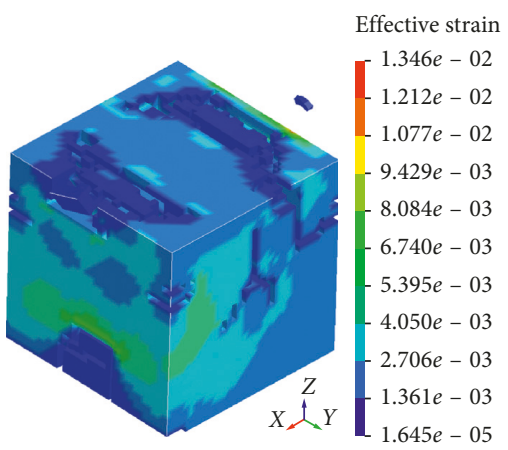

(f)

Figure 6: Relationship between effective strain and impact velocity of coal rock. (a) $v=2.08 \mathrm{~m} / \mathrm{s}$. (b) $v=2.94 \mathrm{~m} / \mathrm{s}$. (c) $v=3.60 \mathrm{~m} / \mathrm{s}$. (d) $v=4.15 \mathrm{~m} / \mathrm{s}$. (e) $v=4.64 \mathrm{~m} / \mathrm{s}$. (f) $v=5.48 \mathrm{~m} / \mathrm{s}$.

of the impact surface at different impact velocities, as shown in Figure 7.

It can be seen from Figure 7 that when the impact velocity is $2.08 \mathrm{~m} / \mathrm{s}$ or $2.94 \mathrm{~m} / \mathrm{s}$, there is no obvious deformation in the bearing surface area. With the increase of the initial velocity given to the cylinder, the displacement of the bearing surface area gradually increases, and the rate of increase gradually increases. There is a positive correlation between the displacement and the impact velocity of the bearing surface area. This is because the greater the impact velocity is, the greater the impact energy given to the coalrock model is, and the greater the damage produced is, appearing macroscopically as the increase of displacement. As the initial velocity increases, the displacement of the crossed area of the coal-rock model gradually increases. The displacement in the crossed area has a positive correlation with the impact velocity. From the analysis on the nonbearing surface area, the displacement of the coal-rock model in this area is close to zero, so the displacement of the nonbearing surface area has no obvious correlation with the impact velocity. Therefore, the variation trend of displacement of the bearing surface area is consistent with the variation trend of displacement of the crossed area. The displacement of the two regions increases with the increase of loading speed. When the impact velocity is relatively small, there is no clear dividing line between the displacements of the bearing surface area and the crossed area. When the impact velocity reaches $3.60 \mathrm{~m} / \mathrm{s}$, the displacements of the two regions have a dividing line, and the displacement in

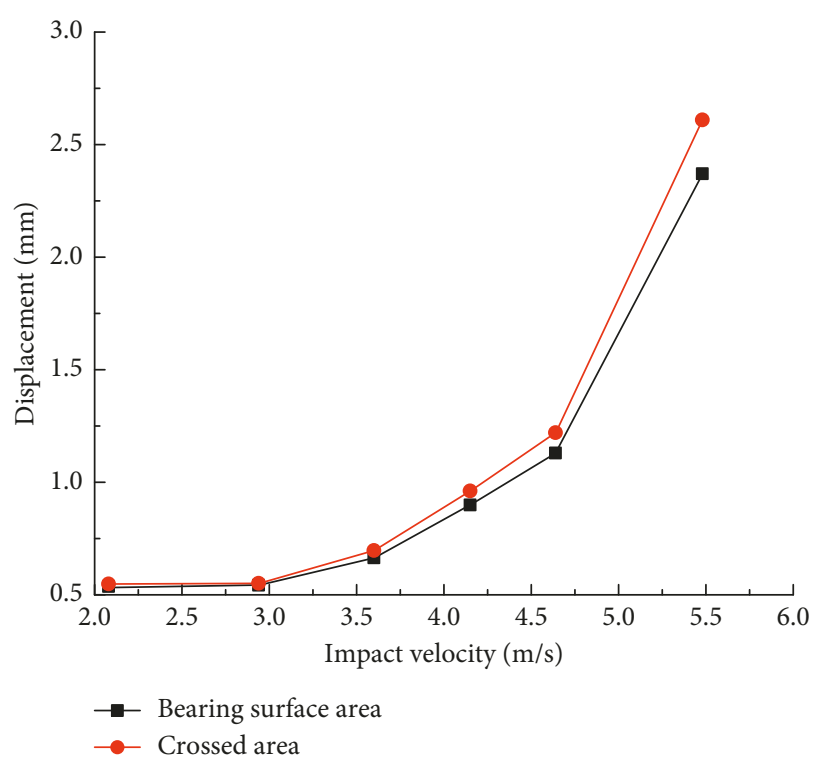

Figure 7: Displacement of impact surface at different impact velocities.

the crossed area is larger than that in the bearing surface area. This is due to the shear stress in the crossed area, which is more likely to cause damage and failure.

2.2.2. Influence of Constraint Static Load on Impact Damage of Coal-Rock Model. The simulation conditions are as 
follows: the impact velocity given to the cylinder was $3.60 \mathrm{~m} /$ $s$ and the static loading imposed on the surface was $0-5 \mathrm{MPa}$ respectively. The effective strain cloud profile along the constraint direction after impact was obtained, as shown in Figure 8. When $q=0 \mathrm{MPa}$, the crossed area is damaged and destroyed after a single impact, showing the sample failure. Compression deformation occurs in the impact zone and a small number of sample failures occur in the sample. When $q=1-4 \mathrm{MPa}$, the sample is subjected to constraint static load, and no sample failure occurs after a single impact. The kinetic energy is mainly converted into strain energy. With the increase of constrain static load, the effective strain value increases gradually after impact, and the maximum strain value concentrates in the middle of the sample. When $q=5 \mathrm{MPa}$, obvious damage and failures occur in the sample after impact, the failure area of the sample is connected, and the sample loses the ability to resist the reimpact.

Through data analysis, the relationship curve between displacement and constraint static load of the bearing surface area and the crossed area under the action of the same impact velocity can be obtained, as shown in Figure 9.

From the analysis on the displacement of the bearing surface area, it can be seen that when the constraint static load is $0 \mathrm{MPa}$, the bearing surface area shows obvious deformation. The surface displacement decreases after static load is applied. The displacement of the crossed area decreases faster than that of the bearing surface area. When the constraint static load is $1 \mathrm{MPa}$ to $4 \mathrm{MPa}$, the displacement of the bearing surface area and crossed area mainly unchanged with the increase of the constraint static load, and both displacement values are near to zero. When the constraint static load is $5 \mathrm{MPa}$, the maximum compression strength of the coal and rock is exceeded, and the coal and rock collapse. The surface displacement of coal sample increases rapidly. The displacement value of the crossed area increases faster than that of the bearing surface area. Totally, the displacements of the bearing surface area and the crossed area are affected by the action of the constraint static load. Within the range of $0-4 \mathrm{MPa}$ of constraint static load, the displacement decreases firstly and then remains constant with the increase of constraint static load. When the constraint static load is $5 \mathrm{MPa}$, the collapse will suddenly occur.

There is a threshold value for the rock studied by previous scholars, and when a certain threshold value is exceeded, a collapse at a stroke will occur. The above phenomenon shows that when the constraint static load is within the uniaxial compression strength of the coal-rock model, the improvement of the constraint static load can effectively enhance the impact resistance of the coal-rock model. When the constraint static load reaches or exceeds the uniaxial compression strength of the coal-rock model, the coal-rock model will suddenly collapse.

2.2.3. Coal-Rock Damage Simulation under Cyclic Impact. The numerical simulation software LS-DYNA is used to simulate the cyclic impact of coal and rock. In the numerical simulation, the impact velocity was $3.6 \mathrm{~m} / \mathrm{s}$. Before each cyclic impact, the coal and rock maintained the property after the last impact, and the velocity remained constant during the cyclic impact process. The simulation results of cyclic impact effective strain are shown in Figure 10. With the increase of the number of cyclic impact, the damage amount of the sample increases gradually. Macroscopic damage occurred in the sample after 5 cycles, and the sample lost the ability to resist damage. After the first impact, no failure was found in each unit of the sample, and the sample remained intact. After the second impact, element failure occurred at the boundary around the sample. After the third impact, the number of unit failures around the sample increased. The damage of the sample was further increased. After the fourth impact, two obvious cracks formed in the middle of the sample, and the internal damage of the sample occurred. The failure range of the element around the sample increased and penetrated through the impact surface, and the number of element failures increased. After the fifth impact, the crack on the impact surface continued to expand, and the number of unit failures continued to increase and expand to the interior. Finally, the sample was pulled off from the middle, losing the ability to resist the second impact.

The relationship between the effective strain of the sample and the impact numbers in the cyclic impact process is shown in Figure 11. As can be seen from Figure 11, the effective strain of the sample increases with the increase of impact number. The effective strain has the characteristics of stage, including deceleration growth stage and acceleration growth stage. The relationship between effective strain and impact times is a cubic function, and the correlation coefficient is 0.962 .

\section{Coal-Rock Damage Test under One- Dimensional Dynamic and Static Loading}

3.1. Statistical Description of Coal-Rock Damage Quantity. The macroscopic catastrophe of rock material originates from its mesodamage evolution. The damage quantity of rock materials can reflect the degree of rock failure when rock materials are subjected to load action. Under the action of certain loads, the internal defects of the rock will gradually evolve into microcracks and forming macroscopic catastrophes, resulting in the changes of the rock's elastic modulus, ultrasonic wave velocity, and other parameters. The microscopic damage characteristics of rock materials are mainly represented by acousto-optic electromagnetic signals, which can reflect the evolution process of internal damage of rock materials [16]. At present, the research methods of rock material damage characteristics include the following categories: the statistics of rock damage quantity based on ultrasonic detection technology; the rock damage research based on nuclear magnetic resonance technology $[17,18]$; rock damage positioning research based on acoustic emission [19-21]; evolution study of rock temperature field based on infrared thermal imaging technology $[22,23]$; simulation of rock damage under impact load based on ANSYS/LS-DYNA or other numerical software [24, 25]; and research on digital speckle techniques for rock failure and 


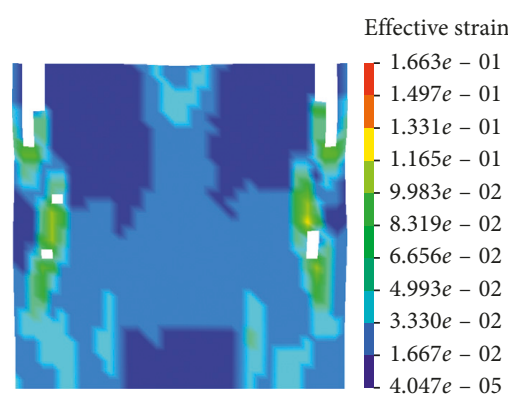

(a)

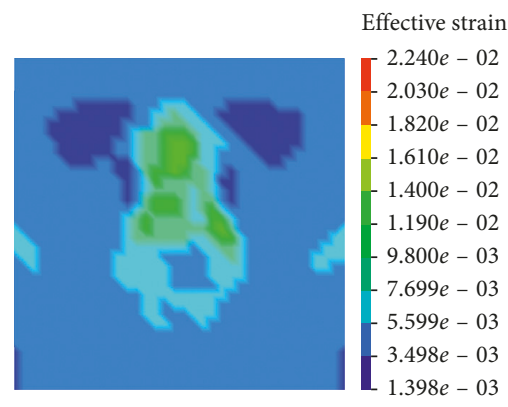

(d)

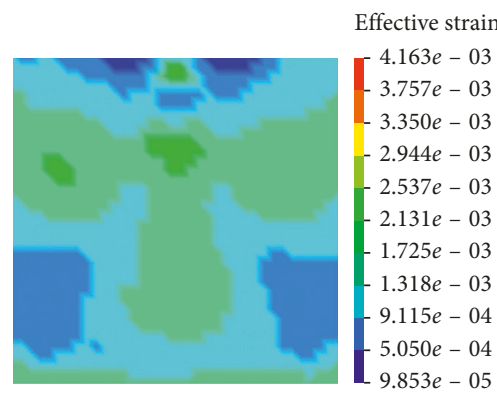

(b)

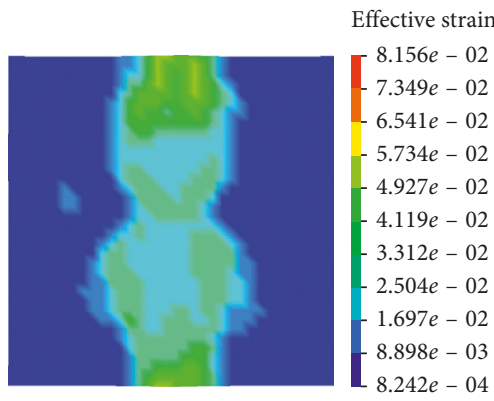

(e)

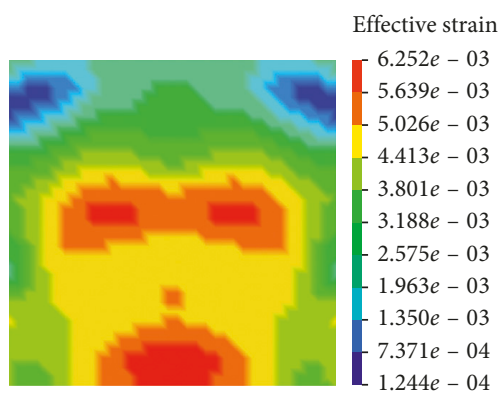

(c)

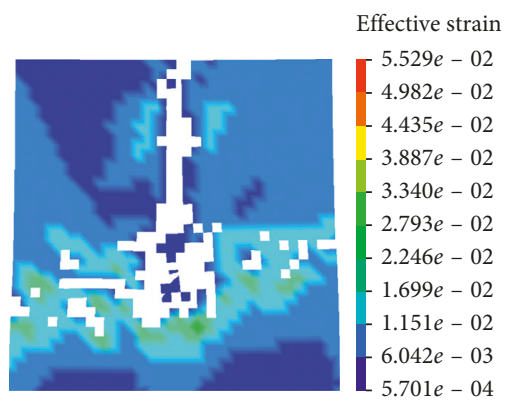

(f)

FiguRE 8: Relationship between effective strain and constraint static load of impact of coal rock. (a) $q=0 \mathrm{MPa}$. (b) $q=1 \mathrm{MPa}$. (c) $q=2 \mathrm{MPa}$. (d) $q=3 \mathrm{MPa}$. (e) $q=4 \mathrm{MPa}$. (f) $q=5 \mathrm{MPa}$.

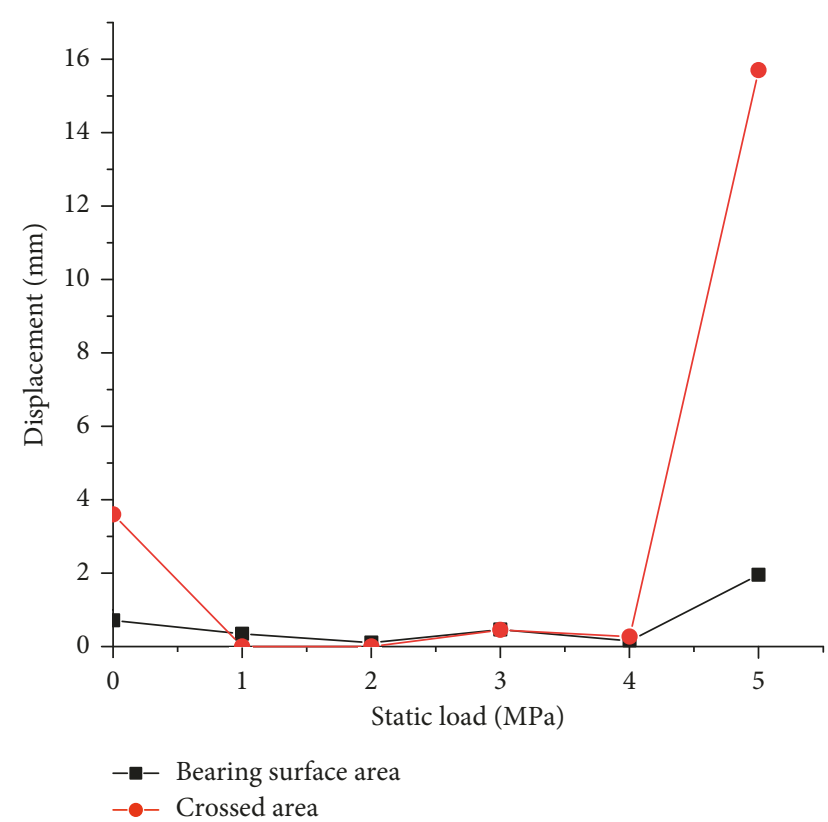

Figure 9: Displacement of impact surface under different loads.

research on constitutive model of rock failure under impact loads [26, 27].

It is difficult to observe and calculate rock damage directly under existing technology, so it is necessary to define the damage quantity. The current methods for defining the damage quantity mainly include the following: the damage scalar defined by microcrack area, the damage tensor defined by microcrack configuration, and the damage variable defined by the change of elastic modulus [28, 29]. It is difficult to intuitively describe and measure the microcrack area or microcrack configuration, but the damage variable defined by the change of elastic modulus can be used to define the damage variable of the rock through the ultrasonic wave velocity. Rock materials will have different degrees of damage after being subjected to impact loads. The damage process will be accompanied by varying degrees of acoustic characteristics and ultrasonic propagation parameters. The relationship between ultrasonic wave velocity and damage variables of rock materials will be established to calculate the quantity change factor of internal structure at the time of impact for rock materials and then used to indirectly make statistics for the damage variables of rock materials.

In order to study the influence of dynamic impact on coal-rock damage under unilateral constraint conditions, the initial wave velocity of coal rock is $V_{0}$, and the wave velocity is $V_{n}$ after the coal rock is subjected to external loading, and then the damage quantity of coal and rock is [11]

$$
D_{n}=1-\left(\frac{V_{n}}{V_{0}}\right)^{2} \text {. }
$$

3.2. Test Equipment. Figure 12 shows a test device based on a constraint pendulum impact dynamic loading. The device consists of a frame, a pendulum, a dial, and a constraint loading mechanism. The constrained loading auxiliary device can be used to carry out one-dimensional static loading of coal and rock in different sizes. The pendulum can be used to produce impact loads of different sizes on the coal and rock by adjusting the angle of the pendulum. As shown in 


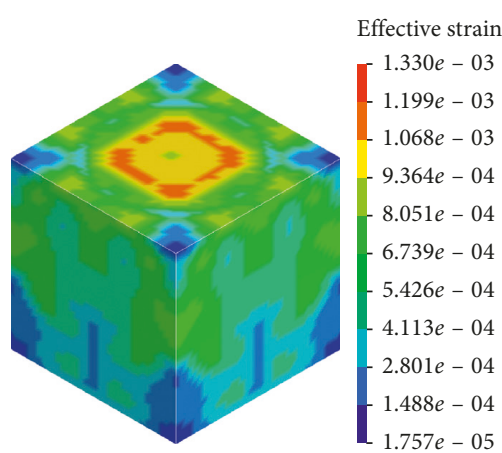

(a)

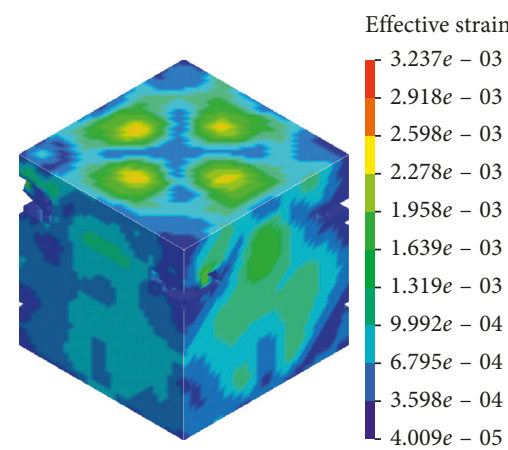

(b)

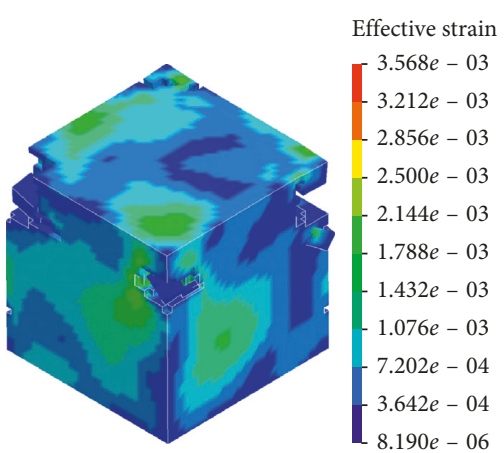

(c)

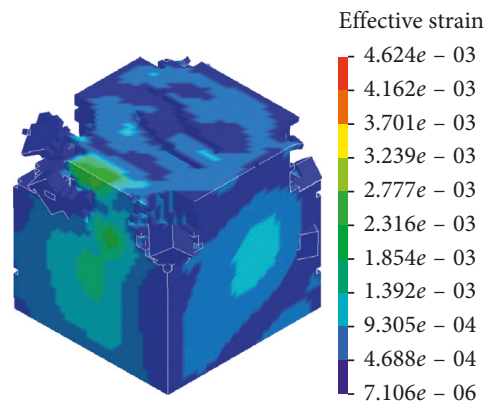

(d)

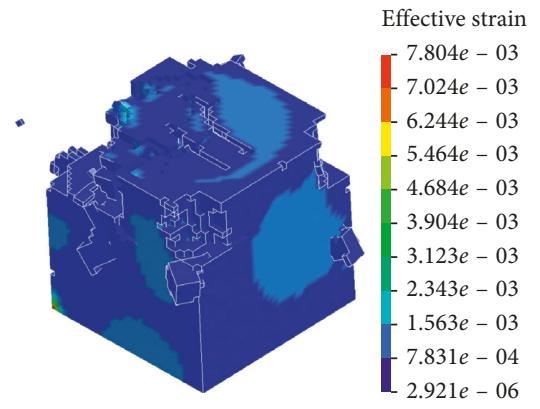

(e)

Figure 10: Effective strain of sample under cyclic impact. (a) No. 1. (b) No. 2. (c) No. 3. (d) No. 4. (e) No. 5.

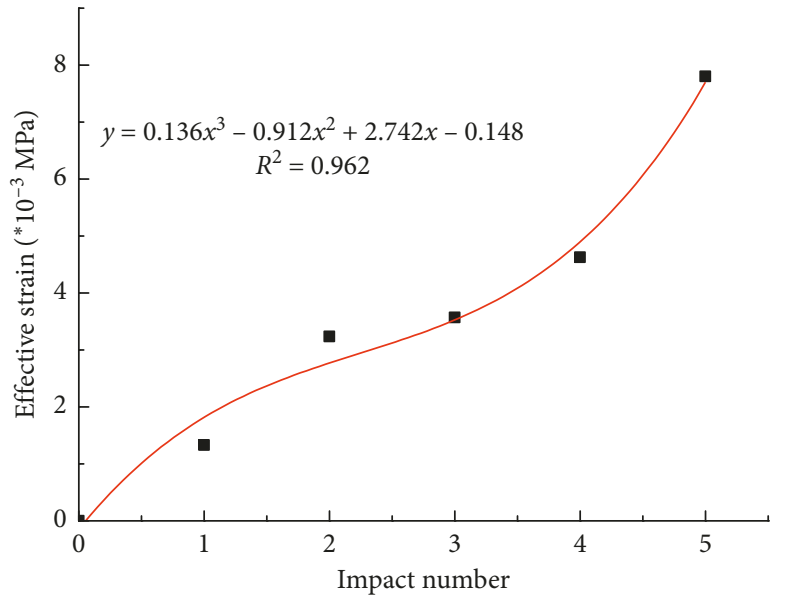

- Effective strain

Figure 11: Relationship between effective strain and impact number.

Figure 12, the pendulum is a cylinder and is connected with the bearing via a pendulum rod. When calculating the impact energy of the pendulum on the coal sample, the equivalent mass of the pendulum and the pendulum rod must be considered (the pendulum rod has greater influence on the equivalent mass, while other components of the equipment have less influence) [30]. The actual measurement shows that the effective length of the pendulum rod $L=0.73 \mathrm{~m}$; the mass of the pendulum rod $m_{2}=0.457 \mathrm{~kg}$; the pendulum mass $m_{1}=1.303 \mathrm{~kg}$; and the pendulum diameter $d=0.06 \mathrm{~m}$.
Pendulum rod inertia:

$$
I^{\prime}=\frac{1}{3} m_{2} L^{2}=0.0812 \mathrm{~kg} \cdot \mathrm{m}^{2}
$$

Equivalent mass:

$$
m=m_{1}+\frac{I^{\prime}}{L_{2}}=1.455 \mathrm{~kg} .
$$

The impact load given to rock materials is the result of the action of damage force and time, and the impulse is a physical quantity describing the time cumulative effect of the force on the object. Therefore, it is more representative to represent the impact energy by impulse. As the current testing method cannot accurately measure the impact time of the pendulum on the coal sample, according to the relationship between impulse $I$ and momentum, we may know

$$
I=m v_{1}-m v_{2} .
$$

When the initial velocity $v_{1}$ is zero, the direction is ignored; then, we can obtain

$$
I=m v_{2} \text {. }
$$

According to the principle of conservation of energy,

$$
m g h=\frac{1}{2} m v^{2} .
$$

According to formulas (4) and (5), the impulse $I$ can be obtained:

$$
I=m \sqrt{2 g h}
$$




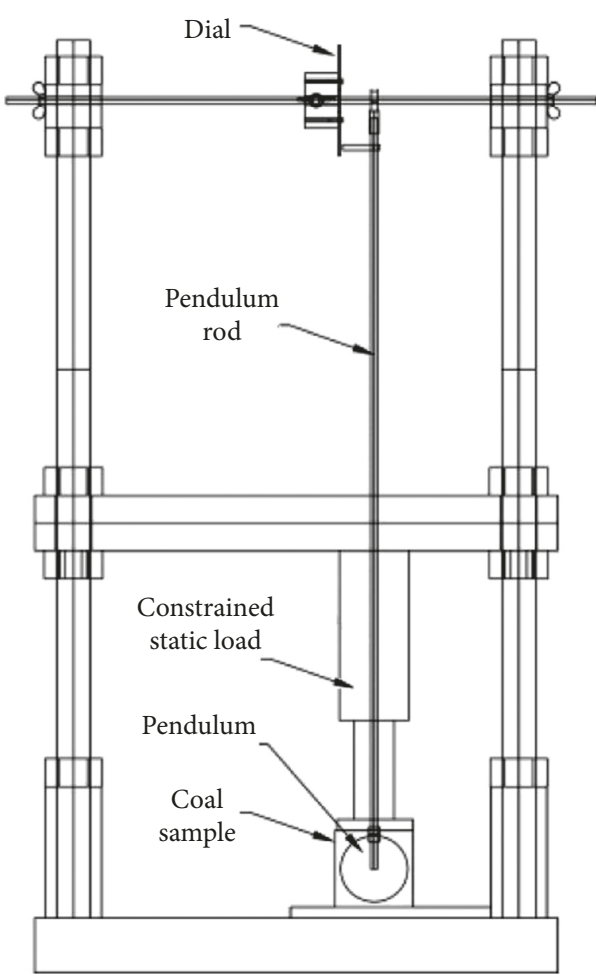

(a)

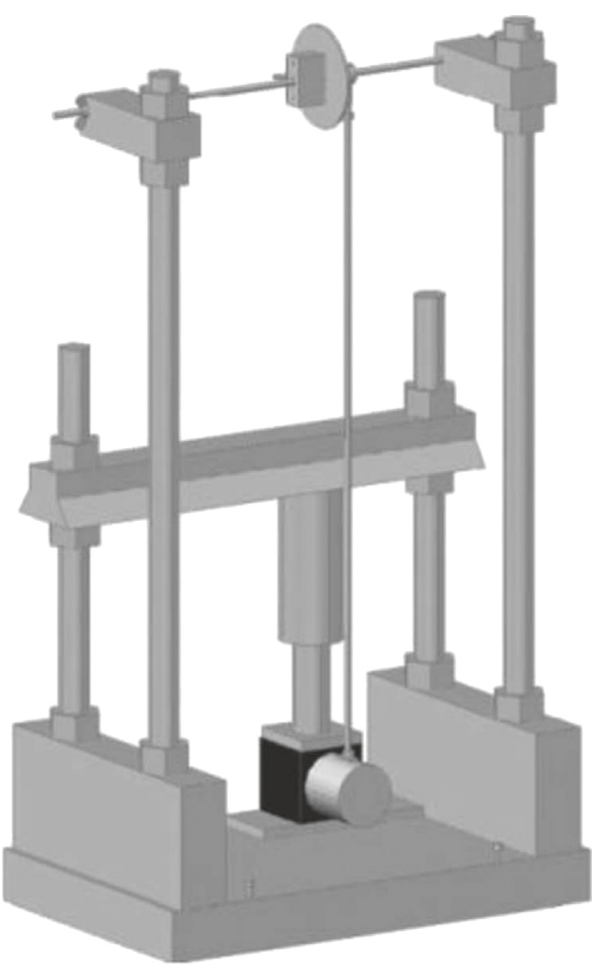

(b)

FIgURE 12: Test situation.

Then, the impulse $I$ on the unit area is

$$
I=\frac{m \sqrt{2 g h}}{0.25 \pi d^{2}} .
$$

The values are substituted in

$$
I=1139.696 \sqrt{h},
$$

where $h$ : pendulum height.

Ultrasonic detection uses HC-U81 concrete ultrasonic detector, the sampling period is $0.05 \mu \mathrm{s} \sim 2.0 \mu \mathrm{s}$, the soundtime measurement accuracy is $0.05 \mu \mathrm{s}$, the amplitude measurement range is $0-170 \mathrm{~dB}$, the test system parameters are shown in Table 3, and Vaseline is used as a coupling agent between sensor and coal sample.

3.3. Sample Preparation. Due to the development of joint cracks in natural coal and difficulty to process, the variation laws of briquette and raw coal have fairly good consistency, and briquette is easy to process; the briquette prepared successfully has minor difference, so the majority of scholars usually adopt the briquette with similar mechanical properties to raw coal as test object [31]. In this test, the briquette is used as the research object, and the briquette is prepared into a cube with a side length of $70 \mathrm{~mm}$ through a briquette production device, as shown in Figure 13.

3.4. Test Program. This test adopts a self-made constraint pendulum impact dynamic loading test device, applies the initial static axial load to the coal sample by a constraint loading mechanism, and uses the pendulum on the device as a power source to apply the impact load on the coal sample. The test was divided into 5 groups with 5 coal samples in each group. According to the uniaxial compression strength of coal samples, it was divided into five initial constraint static loads of $0 \mathrm{MPa}, 1.127 \mathrm{MPa}, 2.254 \mathrm{MPa}, 3.38 \mathrm{MPa}$, and $4.506 \mathrm{MPa}$. The five initial restraint static loads correspond to $0,0.2,0.4,0.6$, and 0.8 times of uniaxial compressive strength, respectively. Each group of coal sample was subjected to one gradient of initial static load, and five coal samples within each group were again subjected to cyclic impact loads until the coal samples failed eventually. The fall height of the pendulum was $22 \mathrm{~cm} \sim 110 \mathrm{~cm}$, having a total of five levels; five coal samples within each group were, respectively, subjected to one level of impact load, each of which corresponds to the size of the unit impulse, as shown in Table 4. Before and after each impact loading, the wave velocity of coal sample was measured and recorded.

\section{Evolution Laws of Dynamic and Static Loads and Coal-Rock Damage}

4.1. Evolution Relationship between the Magnitude of Impulse and the Coal-Rock Damage. The microcracks inside the coal and rock expand under the action of external loads and cause macroscopic catastrophes. The degree of coal-rock damage is negatively correlated with the ultrasonic wave velocity. Taking the first group of $0 \mathrm{MPa}$ unilateral constraint static load as an example for analysis, five levels of ultrasonic wave velocity are measured through ultrasonic testing device, 
TABLE 3: Setting of system parameters of ultrasonic devices.

\begin{tabular}{lcccc}
\hline Sampling period $/ \mu \mathrm{s}$ & Emission voltage/V & Measuring point spacing/mm & Testing surface & Testing method \\
\hline 0.5 & 500 & 70 & Surface & Relative measuring method \\
\hline
\end{tabular}

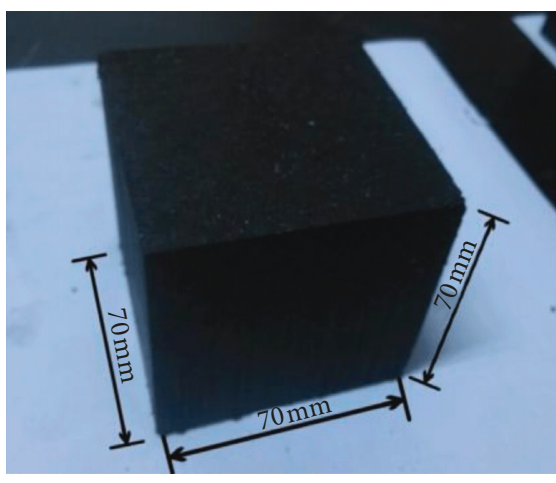

(a)

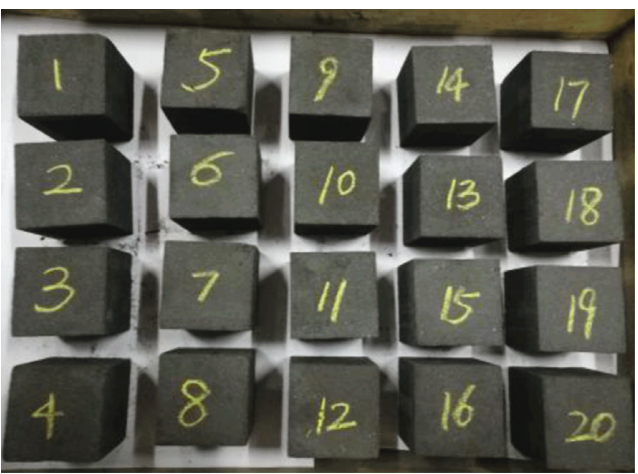

(b)

Figure 13: Test Coal Sample. (a) Size of briquette. (b) Briquette samples.

TABLE 4: Relationship between impulse per unit area and pendulum height.

\begin{tabular}{lc}
\hline Height $h / \mathrm{m}$ & ${\text { Impulse per unit area } \mathrm{I} / \mathrm{N} \cdot \mathrm{s} \cdot \mathrm{m}^{-2}}^{-22}$ \\
0.44 & 535 \\
0.66 & 756 \\
0.88 & 926 \\
1.1 & 1069 \\
\hline
\end{tabular}

using equation (9) to obtain the coal-rock damage quantity $D_{n}$. Then, the curve of fitting relationship between $D_{n}$ and the impact number with different levels can be obtained, as shown in Figure 14.

\subsubsection{Cumulative Effect of Coal-Rock Damage Quantity.} It can be seen from Figure 14 that the fitting curve of coalrock damage under five levels of impulse loadings gradually increases with the increase of the number of cyclic impacts, and the cumulative damage quantity $D_{n}$ of coal and rock increases with the increase of the number of cyclic impacts. The constraint static load and loading methods of five levels of impulse loading tests are the same. Therefore, the reason of the change in the coal-rock damage quantity is the number of cyclic impacts and the magnitude of impulse. The coal-rock damage quantity under five levels of impulse loading increases with the increase of the number of cyclic impacts, and the growth rate is related to the magnitude of impulse. This is because each impulse impact loading is an effective impact on coal and rock, and the internal microcracks of coal and rock have the propagation under the action of external loads, and the tensile stress at the tip of the microcracks inside the coal and rock begins to expand, forms crack clusters, produces crack penetrations, and eventually leads to macroscopic failure. The process of the microcrack propagation is continuous under cyclic impact loading

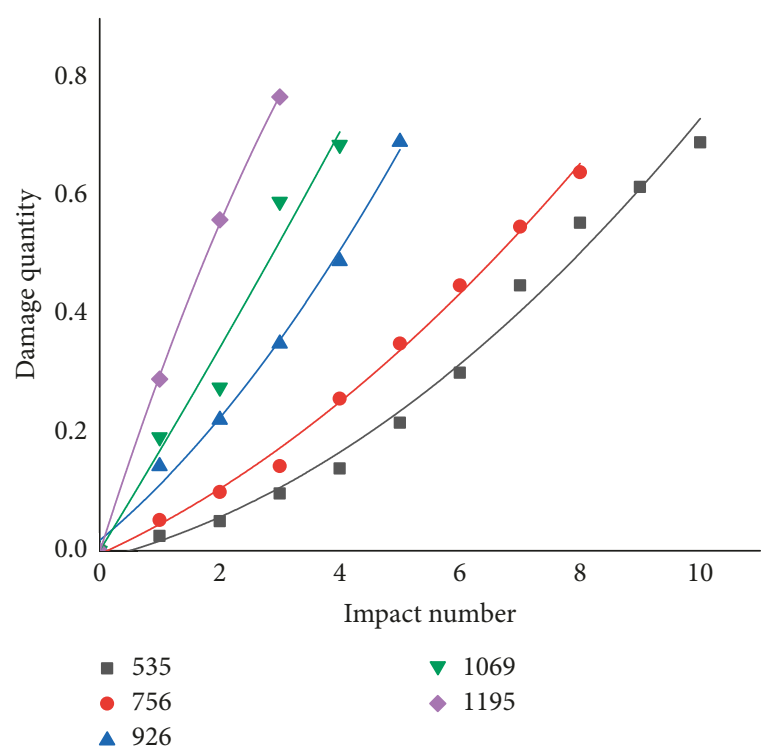

FIgURE 14: Relationship between damage quantity and number of impulse cyclic impact of different levels.

conditions, and the microscopic cracks finally expand to form macroscopic crack failure. From the point of view of ultrasonic wave velocity, the wave velocity is continuously reduced, so the coal-rock damage quantity continues to increase.

4.1.2. Variation Trend of Coal-Rock Damage. It can be seen from Figure 14 that the upward trend of the fitting curve of the coal-rock damage quantity under five levels of impulse loads is approximately proportional to the linear growth. The constraint static loads and loading methods of five levels of impulse loading tests are the same. Therefore, the reason of different failure trends in coal-rock damage is the different magnitude of impulse. When the impact load and the static 
load are constant, the number and extent degree of microcracks determine the subsequent propagation process of the microcracks inside the coal and rock because the quantity of microcracks inside the coal and rock is significantly reduced after multiple cyclic impacts. The new crack clusters and the penetrating cracks are more difficult to form, making the failure velocity of coal and rock not increase or even decrease. However, due to the continuous propagation of the microcracks, the original crack clusters continue to expand into the penetrating cracks under the action of cyclic impact. The microcracks form new crack clusters, thereby increasing the degree of coal-rock damage. The number and complexity of microcracks in coal and rock increase linearly with the increase of impact times, and the porosity of coal and rock increases linearly with the increase of impact times. As a result, the damage of coal and rock increases linearly with the increase of impact times. When the size of static load is the same, under the action of cyclic impact, each impact causes the coal and rock subjected to a greater impact load to be damaged more quickly. Macroscopically, the fitting curve of coal-rock damage quantity increases with the increase of the impulse.

4.1.3. Differentiation Effect of Different Levels of Impulse Loading on the Coal-Rock Damage Quantity. From the longitudinal analysis of the coal-rock damage quantity under different levels of impulse in Figure 14, the coal-rock damage quantity under different levels of impulse loading has a differentiation effect at the first impact, and the greater the loading of the impulse, the greater the damage of the coal and rock. This is because when the first impulse loading is carried out, the microcracks within the large-impulse-loaded coal rock have a greater degree of microcracks propagation and the degree of the coal-rock damage is large, and the coalrock microcrack propagation process is continuous, so that the damage degree of large-impulse-loaded coal rock is getting larger and larger and the degree of differentiation of coal and rock is also getting larger and larger. When the third impact occurs, the coal and rock with the largest impulse loading has eventual failure. At this time, the degree of differentiation of the coal and rock loaded with different levels of impulse loading reaches its maximum value.

\subsubsection{Coal-Rock Eventual Failure Zone under Different Levels} of Impulse Loading. It can be seen from Figure 14 that the cumulative quantity of coal-rock damage increases with the increase of the impact number; while the ultimate failure degree of coal and rock with different levels of impulse loading is close, the damage quantity range of coal and rock with five levels of impulse loading is about $0.65 \sim 0.75$. It can be considered that this zone is a coal-rock eventual failure zone under $0 \mathrm{MPa}$ constraint static load. If the degree of coal-rock damage wants to reach the eventual failure zone, the larger the impulse loading is, the less time it takes for impact loading, and this is because the larger impulse loading makes the faster propagation speed of microcracks within the coal and rock, causing the failure rate of coal and rock faster.
4.1.5. Influence of Cumulative Impulses on Coal-Rock Damage Quantity. The cumulative impulse is the mutual accumulation of multiple impulses, namely, the secondary cumulative impulse is the accumulation of the first two impulses. The external reason of coal-rock damage caused by coal-rock microcracks propagation is the cumulative effect of impulses. The curve of fitting relationship between the coal-rock damage quantity $D_{n}$ and the cumulative impulse can be obtained, as shown in Figure 15.

All the five levels of impulse loading tests are constant type impulse cyclic impact tests. The constraint conditions are all unconstrained. Therefore, the difference condition of this test is the magnitude of the single impact impulse. It can be seen from Figure 15 that if the cumulative impulses are the same, the failure velocity of coal and rock is faster when the single impact impulse is larger. Taking the cumulative impulse of $3500 \mathrm{~N} \cdot \mathrm{s} \cdot \mathrm{m}^{-2}$ as an example, when the cumulative impulse is $3500 \mathrm{~N} \cdot \mathrm{s} \cdot \mathrm{m}^{-2}$, the fifth level of impulse loading of coal and rock completes the eventual damage and failure, while the damage quantity of other lower single impulse decreases in turn and the degree of damage and failure is smaller. If all the five levels of impulse loaded of coal and rock complete the eventual damage and failure, the coal and rock with a lower single impact impulse require more cumulative impulses, which can be applied in engineering to carry out cyclic impact by applying larger single impulse, thus having more efficient rock breaking.

\subsection{Evolution Relationship of Constraint Static Load and} Coal-Rock Damage. Coal and rock are damaged under external loads. Constrained static loading is one of the factors causing coal-rock failure. This test made a comparison study by applying five groups of different constraint static loads to coal and rock and analyzed the damage and failure laws of coal and rock. The difference in the loading conditions between each group of coal and rock tests was the magnitude of the constraint static load. Substituting the ultrasonic wave velocities of the five groups in the test into equation (9) can obtain the coal-rock damage quantity under different constraint static loads. Through data analysis, the relationship between the coal-rock damage quantity $D_{n}$ under different constraint static loads and the impact number can be obtained, as shown in Figure 16.

\subsubsection{Relationship between the Coal-Rock Damage Quantity} and the Impact Number. From Figure 16, it can be seen that under the conditions of unconstraint static loading, the impact number is 3 to 10 when the coal and rock is completely destroyed; under the conditions of $1.127 \mathrm{MPa}$ constraint static loading, the impact number is 6 to 10 when the coal and rock is completely destroyed; under the conditions of $3.38 \mathrm{MPa}$ constraint static loading, the impact number is 5 to 14 when the coal and rock is completely destroyed; under the conditions of $3.943 \mathrm{MPa}$ constraint static loading, the impact number is 4 to 14 when the coal and rock is completely destroyed; under the conditions of $4.506 \mathrm{MPa}$ constraint static loading, the impact number is 4 to 13 when the coal and rock is completely destroyed. From the statistics of the impact 


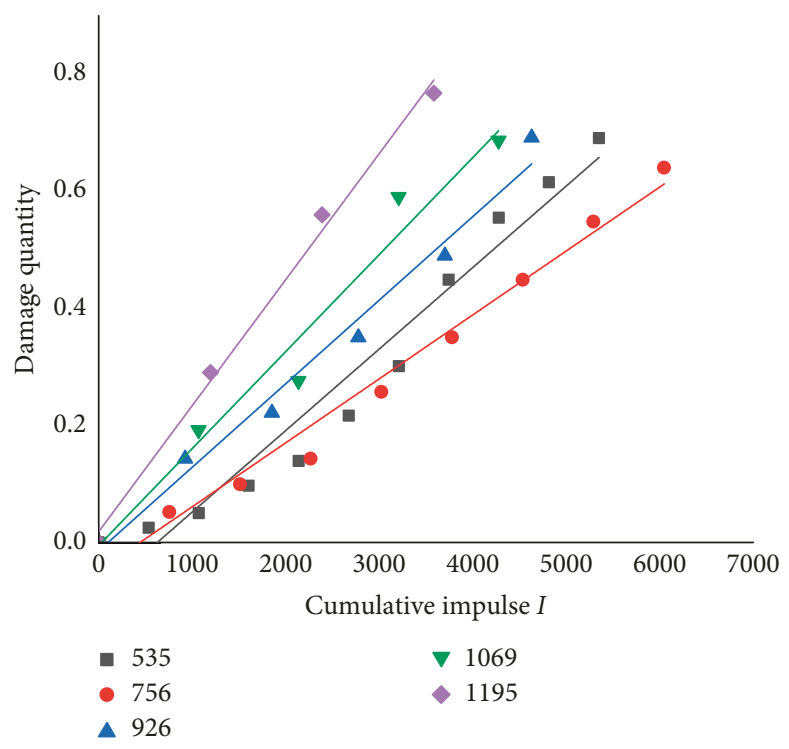

FIGURE 15: Relationship between damage quantity at different levels of impulse and cumulative impulse.

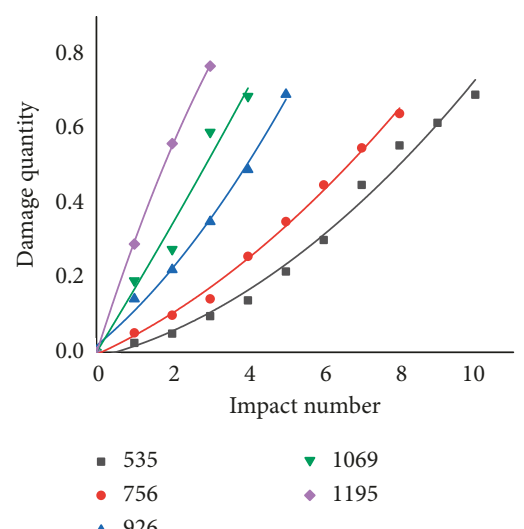

(a)

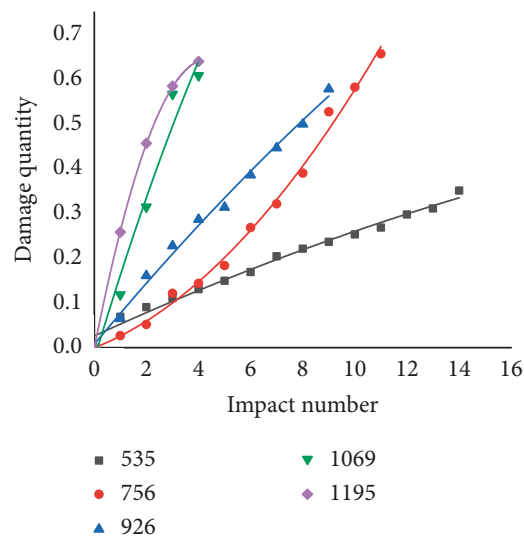

(d)

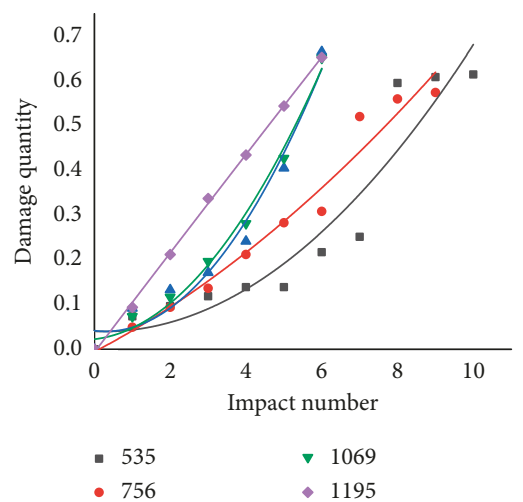

(b)

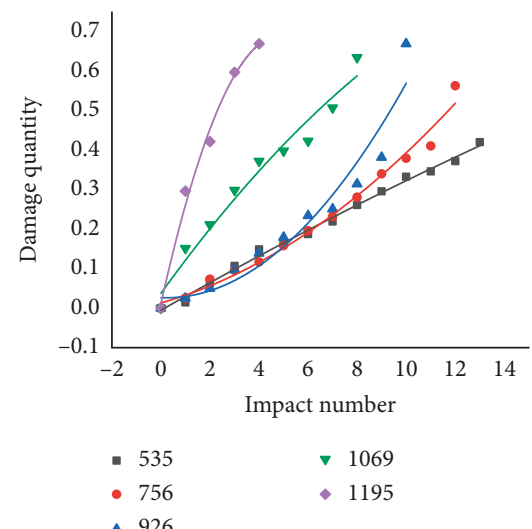

(e)

Figure 16: Relationship between damage quantity and impact number under different constraint static loads. (a) $q=0 \mathrm{MPa}$. (b) $q=1.127 \mathrm{MPa}$. (c) $q=2.254 \mathrm{MPa}$. (d) $q=3.38 \mathrm{MPa}$. (e) $q=4.506 \mathrm{MPa}$.

number, under 0 to $1.127 \mathrm{MPa}$ constraint static load, the impact number required is relatively small when the coal and rock is completely destroyed. Under 3.38 to $4.506 \mathrm{MPa}$ constraint static load, the impact number required is relatively large when the coal and rock is fully damaged. It is assumed that 0 to $1.127 \mathrm{MPa}$ is the low-constraint static-load bearing 

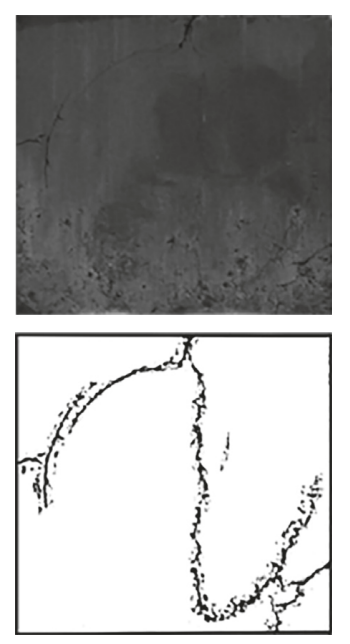

(a)
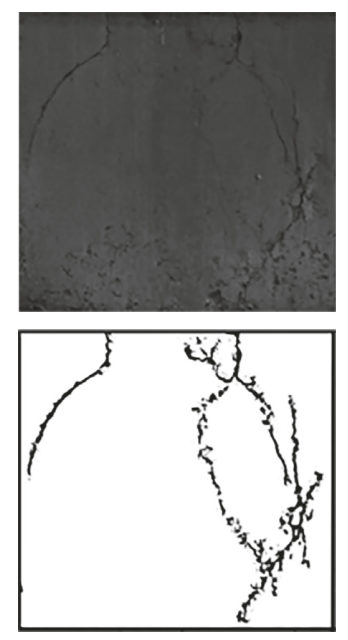

(b)
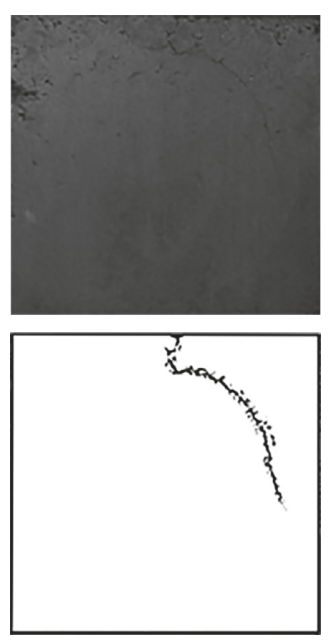

(c)
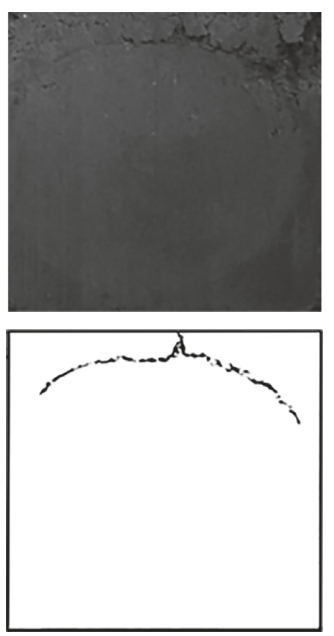

(d)
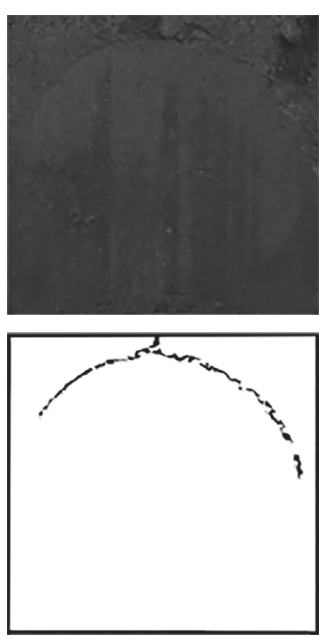

(e)

FiguRe 17: Crack propagation on coal surface. (a) $q=0 \mathrm{MPa}$. (b) $q=1.127 \mathrm{MPa}$. (c) $q=3.38 \mathrm{MPa}$. (d) $q=3.943 \mathrm{MPa}$. (e) $q=4.506 \mathrm{MPa}$.

pressure zone of coal and rock; $3.38 \mathrm{MPa}$ to $4.506 \mathrm{MPa}$ is the high-constraint static-load bearing pressure zone of coal and rock, namely, 0 to $20 \%$ of the uniaxial compression strength of coal and rock is the low-constraint static-load bearing pressure zone, and $40 \%$ to $80 \%$ of the uniaxial compression strength of coal and rock is the high-constraint static-load bearing pressure zone. From the above statistics, it can be seen that the impact number required for the coal and rock failure in the low-constraint static-load bearing pressure zone is smaller, and the impact number required for coal and rock failure in the high-constraint static-load bearing pressure zone is greater. It is possible to achieve the purpose of efficient mining in engineering through the pressure relief of coal and rock in advance.

When the coal and rock are loaded with the same impulse, the constraint static load suppresses the failure and propagation process of the microcracks of the coal and rock, making the microcrack propagation difficult. In macroscopic terms, it is shown that the greater the static load imposed on the coal and rock, the more times of cyclic impact the coal and rock is required when it is fully destroyed.

\subsubsection{Failure Trend of Coal-Rock Damage under Different} Constraint Static Loads. From Figure 16, it can be seen that the fitting curve of coal-rock damage for each level of impulse under different constraint static loads tends to approach the $x$-axis as the constraint static load increases, and the slope of the fitting curve of the coal-rock damage for each level of impulse generally becomes smaller and smaller as the constraint static load increases, which indicates that the increase of constraint static load suppresses the microcrack propagation of coal and rock and slows down the damage process of coal and rock.

4.3. Crack Propagation Law of Coal Surface under Dynamic and Static Load. The impact loading mechanism of this test is cylinder. After the surface of cube coal is impacted, the force surface is the contact surface between coal and cylindrical pendulum. In the test, the boundary of the stressed surface of coal shows crack expansion in different degrees. When the coal is impacted, the shear stress area is formed by the intersection of the stressed surface area and the nonstressed surface area. The existence of shear stress makes the crossed area easy to form cracks.

The degree of fracture expansion on the surface of coal and rock can reflect the degree of damage of coal [10]. The images of crack propagation on impact surface of coal and rock under constraint static load were obtained by means of HD digital camera. Figure 17 shows the crack condition of coal impact surface after four cyclic impacts. Through Photoshop, cracks on the surface of coal and rock were processed, and the sketch drawing of cracks on the surface was obtained.

As can be seen from Figure 17, when the constraint static load is low (Figure 17(a) and 17(b)), a large number of cracks appear in both the crossed area and the stressed surface area, and vertical penetrating cracks appear in the stressed surface area. When the constraint static load is low, the effect of static load on crack propagation is weak. The rigid pad block supporting the specimen is adjacent to the impact surface of the specimen. Therefore, it is easy for the specimen to form vertical penetrating cracks under impact. When the constraint static load is high (Figure 17(c)-17(e)), there are few cracks in the crossed area of coal and rock and no macroscopic cracks in the stressed surface area. This is because the high-constraint static load inhibits the expansion of microcracks in coal and rock, resulting in fewer macroscopic cracks on the surface of coal and rock.

\section{Conclusions}

The main conclusions of this paper are as follows:

(1) The damage quantity of coal and rock has a cumulative effect, which increases with the increase of 
the impact number; the ultimate damage degree of coal and rock loaded with different levels of impulse under the same constraint static load is close, namely, the eventual failure $D_{n}$ of coal and rock is approximately $0.65 \sim 0.75$.

(2) The deformation displacement of coal-rock model increases with the increase of single impact velocity, and the damage quantity of coal and rock increases with the increase of single impulse, which means that increasing single impulse contributes to the microcrack propagation. In engineering, it is possible to perform a cyclic impact by applying a larger single impact impulse so as to efficiently break rock and conserve energy.

(3) The damage quantity of coal and rock decreases with the increase of the constraint static load, indicating that the constraint static load suppresses the microcrack propagation. In engineering, it is possible to enhance the impact resistance of rock engineering by increasing the constraint static load and to achieve the purpose of high-efficiency mining through pressure relief.

(4) The coal-rock model shows that when the constraint static load reaches or exceeds the uniaxial compression strength of the coal-rock model, the coalrock model will suffer the collapse at a stroke.

\section{Data Availability}

The data used to support the findings of this study are available from the corresponding author upon request.

\section{Conflicts of Interest}

The authors declare that they have no conflicts of interest.

\section{Acknowledgments}

The authors gratefully acknowledge the support of the Open Fund of State Key Laboratory of Oil and Gas Reservoir Geology and Exploitation (Southwest Petroleum University) (grant no. PLN1304), the National Key R\&D Program of China (2018YFC1504800), the National Natural Science Foundation of China (grant no. 51474220), and the National Key R\&D Program of China (grant no. 2018YFC0808403).

\section{References}

[1] A. V. Dyskin, "On the role of stress fluctuations in brittle fracture," International Journal of Fracture, vol. 100, no. 1, pp. 29-53, 1999.

[2] R. Shan, Y. Jiang, and B. Li, "Obtaining dynamic complete stress-strain curves for rock using the split Hopkinson pressure Bar technique," International Journal of Rock Mechanics and Mining Sciences, vol. 37, no. 6, pp. 983-992, 2000.

[3] L. Weng, X. Li, A. Taheri, Q. Wu, and X. Xie, "Fracture evolution around a cavity in brittle rock under uniaxial compression and coupled static-dynamic loads," Rock Mechanics and Rock Engineering, vol. 51, no. 2, pp. 531-545, 2018.
[4] T. Yin, L. Bai, S. Li, X. au, and S. Zhang, "Effect of thermal treatment on the mode I fracture toughness of granite under dynamic and static coupling load," Engineering Fracture Mechanics, vol. 199, pp. 143-158, 2018.

[5] K. Du, X.-b.M. Tao, and J. Zhou, "Experimental study of slabbing and rockburst induced by true-triaxial unloading and local dynamic disturbance," Rock Mechanics and Rock Engineering, vol. 49, no. 9, pp. 3437-3453, 2016.

[6] S. H. Li, W. C. Zhu, L. L. Niu, M. Yu, and C. F. Chen, "Dynamic characteristics of green sandstone subjected to repetitive impact loading: phenomena and mechanisms," Rock Mechanics \& Rock Engineering, vol. 51, no. 4, pp. 1-16, 2018.

[7] A. Fakhimi, J. P. Azhdari, and J. Kimberley, "Physical and numerical evaluation of rock strength in split Hopkinson pressure bar testing," Computers and Geotechnics, vol. 102, pp. 1-11, 2018.

[8] J. F. Jin, X. B. Li, G. S. Wang, and Z. Q. Yin, "Failure modes and mechanisms of sandstone under cyclic impact loadings," Journal of Central South University (Science and Technology), vol. 43, no. 4, pp. 1453-1461, 2012.

[9] W. C. Zhu, Y. Bai, and L. L. Niu, "Numerical simulation on rock failure under combined static and dynamic loading during SHPB tests," International Journal of Impact Engineering, vol. 49, pp. 142-157, 2012.

[10] H. B. Zhao, Z. W. Wang, H. Zhang et al., "Effects of dynamic loads on development of internal microstructure and distribution of new surface fractures of coal," Chinese Journal of Rock Mechanics and Engineering, vol. 35, no. 5, pp. 971-979, 2016.

[11] H. Yavuz, R. K. Tufekci, and H. Cevizci, "Predicting the dynamic compressive strength of carbonate rocks from quasistatic properties," Experimental Mechanics, vol. 53, no. 3, pp. 367-376, 2013.

[12] U. S. Lindholm, L. M. Yeakley, and A. Nagy, "The dynamic strength and fracture properties of dresser basalt," International Journal of Rock Mechanics and Mining Sciences and Geomechanics Abstracts, vol. 11, no. 2, pp. 181-191, 1974.

[13] S. Kinoshita, K. Sato, and M. Kawakita, "On the mechanical behavior of rocks under impulsive loading," Bulletin of the Faculty of Engineering Hokkaido University, no. 83, pp. 51-62, 1977.

[14] T. J. Holmquist and G. R. Johnson, "A computational constitutive model for glass subjected to large strains, high strain rates and high pressures," Journal of Applied Mechanics, vol. 78, no. 5, article 051003, 2011.

[15] L. Wen, X. B. Li, Q. H. Wu et al., "Dynamic strength of granite porphyry under freezing-thawing cycles," Chinese Journal of Rock Mechanics and Engineering, vol. 34, no. 7, pp. 1297-1306, 2015.

[16] Y. M. Song and X. B. Yang, "Experiment study of temperature evolution characteristics during deformation and destruction process of coal," Chinese Journal of Rock Mechanics and Engineering, vol. 32, no. 7, pp. 1344-1349, 2013.

[17] K. P. Zhou, J. L. Li, Y. J. Xu, and Y. M. Zhang, "Measurement of rock pore structure based on NMR technology," Journal of Central South University (Science and Technology), vol. 43, no. 12, pp. 4796-4800, 2012.

[18] S. X. Feng, J. R. Chai, Z. G. Xu, and Y. Qin, "Evaluating the mesostructural changes of laboratory created soil-rock mixtures using a seepage test based on NMR technology," Journal of Testing and Evaluation, vol. 46, no. 3, pp. 879-891, 2018.

[19] L. Dong, D. Sun, X. Li et al., "Theoretical and experimental studies of localization methodology for $\mathrm{AE}$ and microseismic 
sources without pre-measured wave velocity in mines," IEEE Access, vol. 5, pp. 16818-16828, 2017.

[20] F. J. Zhao, Y. Li, Z. Y. Ye et al., "Research on acoustic emission and electromagnetic emission characteristics of rock fragmentation at different loading rates," Shock and Vibration, vol. 2018, Article ID 4680879, 8 pages, 2018.

[21] Q. Meng, M. Zhang, L. Han, H. Pu, and T. Nie, "Effects of acoustic emission and energy evolution of rock specimens under the uniaxial cyclic loading and unloading compression," Rock Mechanics and Rock Engineering, vol. 49, no. 10, pp. 3873-3886, 2016.

[22] L. Q. Ma, Y. Zhang, H. Sun, S. K. Wang, and A. Najeem, "Experimental study on dependence of infrared radiation on stress for coal fracturing process," Journal of China Coal Society, vol. 42, no. 1, pp. 140-147, 2017.

[23] S. Liu, Z. Xu, J. Wei et al., "Experimental study on microwave radiation from deforming and fracturing rock under loading outdoor," IEEE Transactions on Geoscience \& Remote Sensing, vol. 54, no. 9, pp. 1-10, 2016.

[24] J. Z. Su, Z. W. Huang, Q. J. Long, and C. Y. Liu, “ANSYSbased simulation of fracturing pressure reducing mechanism," Oil \& Gas Geology, vol. 33, no. 4, pp. 640-645, 2012.

[25] T. J. Yan, M. X. Jiang, Y. Zhang, and B. L. Nie, "Study on rock breaking for particle impacting with confining pressure based on ANSYS-LSDYNA," Fault-Block \& Gas Field, vol. 19, no. 2, pp. $240-243,2012$.

[26] L. Mao and F. Chiang, "3D strain mapping in rocks using digital volumetric speckle photography technique," Acta Mechanica, vol. 227, no. 11, pp. 1-17, 2015.

[27] M. Y. Wang, D. S. Xie, J. Li, and N. Zhang, "Dynamic constitutive model for deformation and fracture of deep rock mass," Chinese Journal of Rock Mechanics and Engineering, vol. 32, no. 6, pp. 1112-1120, 2013.

[28] G. S. Yang, J. Sun, and D. Y. Xie, "Damage measurement technique and development of rock," Journal of China Coal Society, vol. 23, no. 4, pp. 67-71, 1998.

[29] M. J. Zhao and D. L. Wu, "Experimental study of damage development in salt rock under uniaxial stress using ultrasonic velocity and acoustic emissions," Applied Sciences-Basel, vol. 8 , no. $4,2018$.

[30] J. B. Tang, "Design and research pendulum impact test equivalent quality," Automobile Applied Technology, vol. 1, no. 1, pp. 5-7, 2014.

[31] H. B. Zhao, T. Wang, H. Zhang et al., "Comparison of local load influence on crack evolution of coal and briquette coal samples," Advances in Civil Engineering, vol. 2018, Article ID 1790785, 12 pages, 2018. 


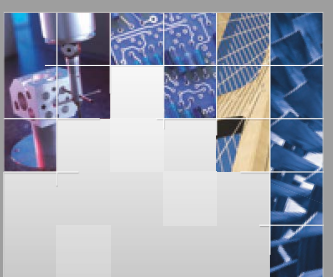

\section{Enfincering}
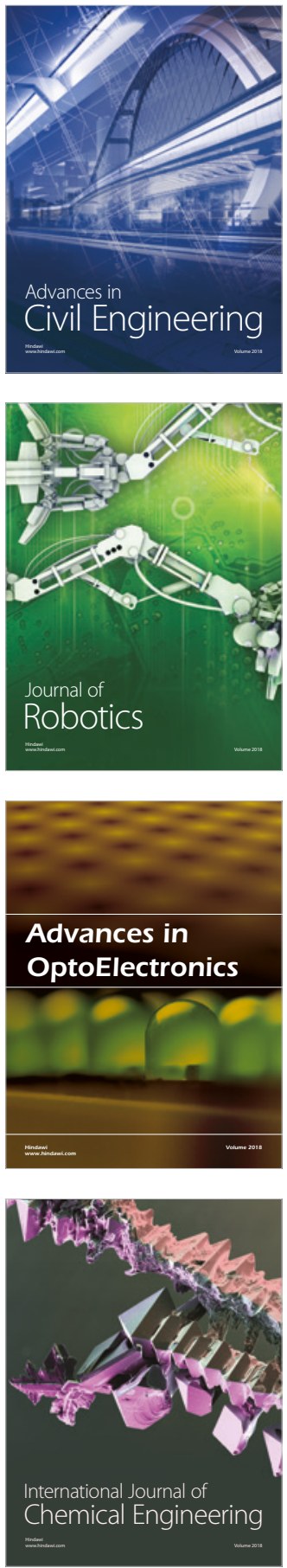

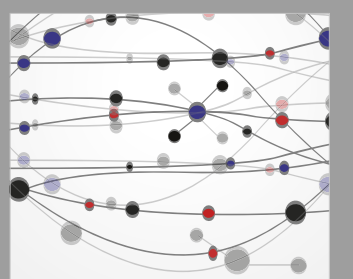

\section{Rotating \\ Machinery}

The Scientific World Journal

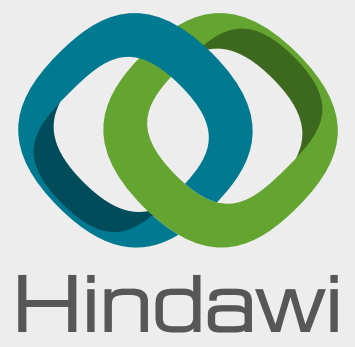

Submit your manuscripts at

www.hindawi.com
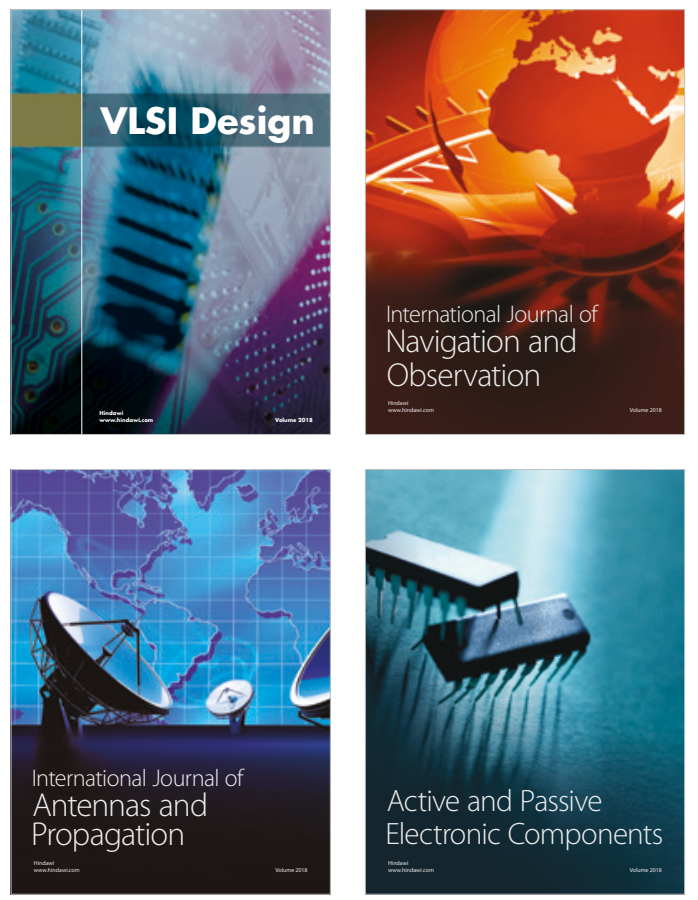
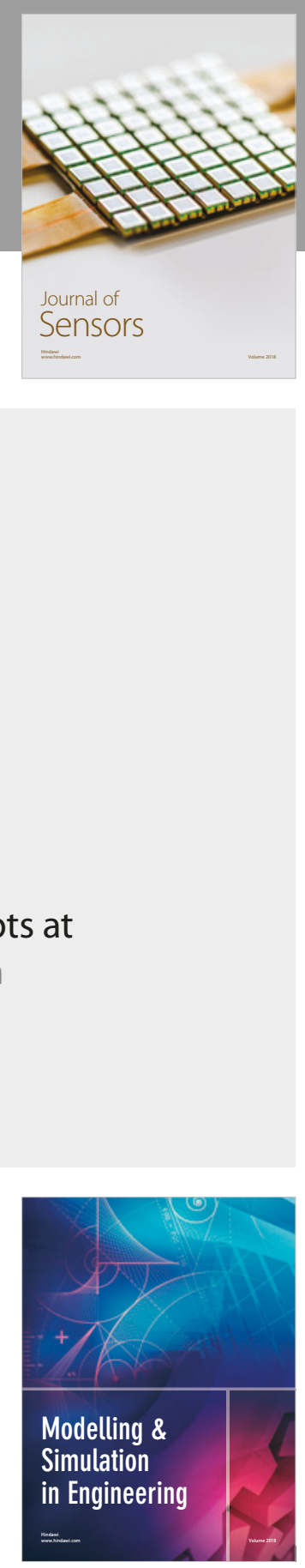

\section{Advances \\ Multimedia}
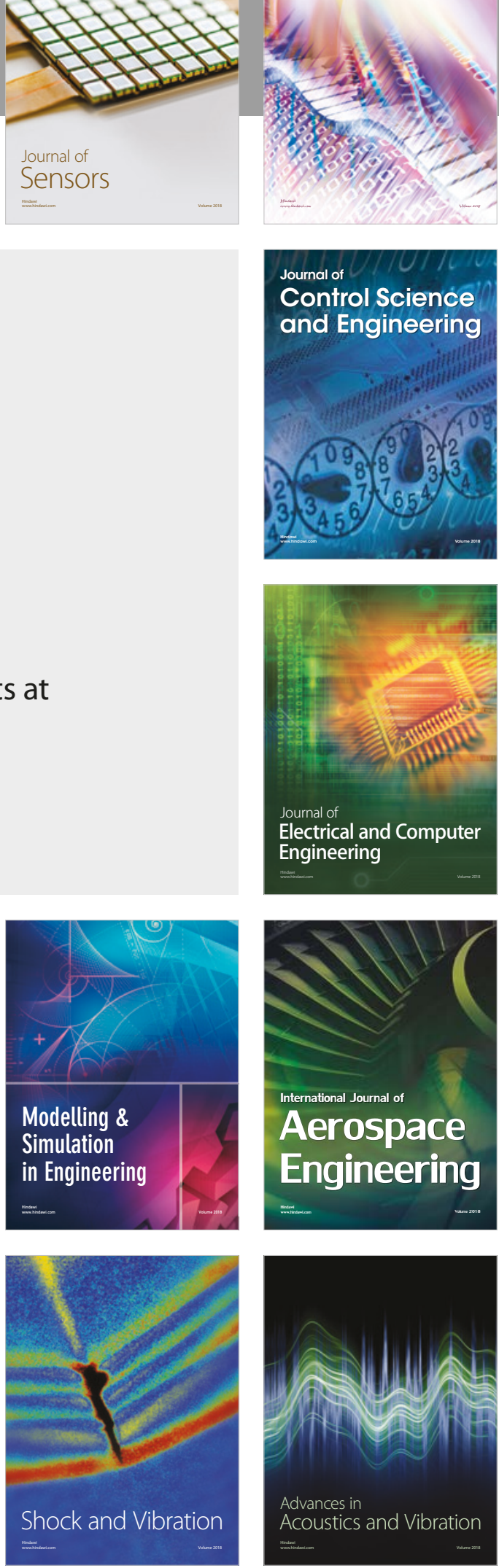